\title{
MARGINAL EFFECTS OF FACTORS INFLUENCING PROCUREMENT RECORDS MANAGEMENT: A SURVEY OF SELECTED PROCURING ENTITIES IN TANZANIA
}

\author{
Bakari Maligwa \\ Mohamed $^{1+}$ \\ Geraldine \\ Arbogast Rasheli ${ }^{2}$ \\ Leonada Rafael \\ Mwagike $^{3}$
}

${ }^{\prime}$ Lecturer, School of Business - Mzumbe University, Tanzania ${ }^{\prime}$ Email:bmmohamed@m $2 u m b e . a c . t \approx$ Tel: +255713593347

${ }^{2, s}$ Senior Lecturer, School of Business - Mzumbe University, Tanzania

'Email: garbogast@maumbe.ac.tz Tel: +255759350540

${ }^{3}$ Email:limwagike@m mumbe.ac.t $\approx$ Tel: +255 784.603722

\section{Article History}

Received: 6 April 2018 Revised: 18 April 2018 Accepted: 20 April 2018 Published: 23 April 2018

\section{Keywords}

Archives

Management

Marginal effects

Procurement

Procuring entities

Records

Tanzania.

\section{ABSTRACT}

This paper estimated marginal effects on dependent variable against independent variables on the management of procurement records in the Tanzania procuring entities (PEs). The study was a survey of selected PEs. Data were collected through structured questionnaires. Sample was arbitrarily set at 200 PEs whereby questionnaires were randomly administered to 200 respondents within 200 PEs found in Dar es Salaam, Dodoma, Morogoro, Pwani, and Tanga. At the end of questionnaires administration the response rates were $83.1 \%$ PEs and $75 \%$ respondents respectively. Based on the results and findings, marginal effects were identified, established and estimated. The study was concluded that: PEs having no equipment and facilities for keeping records are $2.7 \%$ less likely to have proper management of procurement records, PEs with limited equipment and facilities for keeping records are $4.1 \%$ less likely to have proper management of procurement records, and PEs with no security and safety measures in managing records are $1.4 \%$ less likely to have proper management of procurement records, ceteris paribus. On the contrary, procurement records managed by personnel who are knowledgeable and skilled are $1.3 \%$ more likely to be properly managed, procurement records that are managed by competent personnel and who have the on-the-job training on records management are $1.0 \%$ more likely to be properly managed, PEs with available storage space for keeping records, improves management of procurement records by $4.8 \%$, PEs with adequate storage space for keeping all kinds of procurement records, improves management of procurement records by $6.5 \%$, and PEs that have sufficient security and safety measures in managing procurement records, improves management of procurement records by $4.3 \%$ ceteris paribus.

Contribution/ Originality: This paper contributes to the management of procurement records in the Tanzania through the identification, establishment and estimation of marginal effects on the extent of proper management of procurement records in Tanzania. The paper adds value to the body of knowledge in the records and archives management system (RAMS).

\section{INTRODUCTION}

Records [and archives] management (RAM) is an important support tool that enables organisations to comply with legal requirements (Weisinger, 2011). Records are essential to the business of all organisations. They document the work of public authorities and private companies, support their operations and form the basis for the 
many services that are provided by them (Smith, 2007). Records are indispensable for the efficient management of organisations but are often undervalued, ignored or misunderstood (Williams, 2006). The Public Sector Reform Programme (PSRP) introduced in many African countries including Tanzania has consistently emphasized the importance of improving the quality of records management as a basis for decision making, more timely service delivery and financial savings (World Bank and International Records Management Trust, 2005; International Records Management Trust, 2009; Manyambula, 2009).

However, the management of public records in many African countries has been characterized as an area of crisis (IRMT, 1999; WB and IRMT, 2000; IRMT, 2004; Thurston, 2005). In Kenya, for example, records of procurement transactions in many cases were found to be inaccurate or incomplete whilst in some cases they were absent altogether (Njeru, 2015; Nyaboke-Marendi, 2015; Kendo and Getuno, 2016). Poor management of procurement records has been observed in Uganda (Republic of Uganda, 2008; RoU, 2009; RoU, 2010; Tumuhairwe and Ahimbisibwe, 2016; Namukasa, 2017).

\section{STATEMENT OF THE PROBLEM}

Despite of deliberate efforts in ensuring procurement records are efficiently managed and cared - as public records, compliance and performance audits for most of the audited PEs in Tanzania had documented and recorded average compliance levels below the targets (United Republic of Tanzania, 2014a; URT, 2014b; URT, 2015a; URT, 2015b; URT, 2016a; URT, 2016b; URT, 2017a; URT, 2017b). Alongside the documented and recorded below target compliance levels, the audited PEs were observed with weaknesses on the components of the management of procurement records, inter alia: completeness of procurement records; proper arrangement of procurement records; adequacy of space for procurement records; and adequacy of storage facilities and equipment for procurement records (URT, 2014a; URT, 2015a; URT, 2016a; URT, 2017a).

The weaknesses on the completeness of procurement records and proper arrangement of procurement records have been resulted due to inadequate staffing in the procurement functional units (Stephano, 2014) non-compliance with the legislation and regulations (Naluyaga, 2014) and lack of procurement records guidelines contrary to Regulation 88(4) of Government Notice No. 446 of 2013 as amended. These factors, together with inadequate storage space and equipment and facilities for procurement records have rendered most of the Tanzania PEs to document and record improper management of procurement records (URT, 2014a; URT, 2014b; URT, 2015a; URT, 2015b; URT, 2016a; URT, 2016b; URT, 2017a; URT, 2017b). Whatsoever, Tanzania has recognised the impact of improper and inefficient records management on the efficiency of government operations and on accountability and transparency in the public sector and has been working to strengthen its records [and archives] management systems (IRMT, 2011).

The audit weaknesses found in the PPRA audit reports were also observed, documented and recorded in the Controller and Auditor General (CAG) audits (URT, 2014b; URT, 2015b; URT, 2016b; URT, 2017b). This procurement audit trends indicate a clear manifestation of either improper or poor management and care of procurement records within and across the Tanzania PEs audited in the respective financial years. Whilst this is happening; Tanzania is experiencing the existence of the regulatory and institutional reforms and the concerted efforts of the PPRA and the CAG offices in ensuring that compliance with management of procurement records by the PEs is beyond the targeted compliance levels (URT, 2016a). Despite of the known weaknesses, however; the marginal effects of the factors contributing to these weaknesses on proper management of procurement records in the Tanzania PEs have not been studied. Therefore, this paper tries to identify, establish and estimate results for marginal effects based on the dichotomous dependent variable against the independent explanatory variables on the management of procurement records in the Tanzania PEs. 


\section{METHODOLOGY}

\subsection{Study Design, Sample Size, and Data Collection}

This study has used survey method for data collection through structured questionnaires. The study area was Tanzania (mainland) where procuring entities (PEs) were conveniently sampled from Dar es Salaam, Dodoma, Morogoro, Pwani, and Tanga. The initial sample of PEs was arbitrarily set at 200 PEs whereby questionnaires were randomly administered to at least 200 heads of procurement management units (PMUs) and user departments within and across the sampled 200 PEs. At the end of the questionnaires administration it was found that the response rate for the PEs was $54 \%$ and respondents' response rate was $75 \%$ respectively.

\subsection{Units of Analysis and Inquiry}

The units of analysis for this study were the Tanzania PEs. Through the PMUs and the user departments within and across the PEs' institutional arrangements; the PEs do routinely create, receive, use, maintain, archive, or dispose procurement records within and across the procurement business processes and the associated activities. The units of inquiry in his study were the institutional actors that were limitedly found within and across the PEs' institutional arrangements that were directly involved in the activities of management and care of procurement records within the PMUs and user departments.

\subsection{Data Analysis}

Data analysis depends on the nature of data. Data for this study were quantitatively analysed. The envisioned quantitative analysis began with coding and data entry into the Statistical Package for Social Sciences (SPSS) program. Thereafter, SPSS data file was created. The SPSS was considered appropriate since it allowed the researcher to follow clear set of quantitative data analysis procedures that lead to the increased data validity and reliability and demonstrated the relationship between the research variables. The SPSS assisted in producing frequency tables for descriptive analysis. Data were also cleaned for accuracy and consistence. The data were later on exported to the STATA computer software before further analysis. Here also, STATA data file was created. The logistics regression analysis was done using the STATA program to determine the influence and marginal effects that the independent explanatory variables $\left(X_{i}\right)$ have on the dependent variable $(\mathcal{Y}=D)$. The proposed logit model for this study is of the form:

$$
\begin{gathered}
\ln \left(Y^{\prime}\right)=\operatorname{logit}[p(x)]=\ln \frac{p(x)}{1-p(x)} \\
\operatorname{logit}[p(x)]=\ln \frac{p(x)}{1-p(x)}=\beta_{o}+\beta_{1} X_{t}+\beta_{2} X_{2}+\beta_{s} X_{s}+\beta_{4} X_{4}+\varepsilon
\end{gathered}
$$

Where;

$Y=$ Proper management of procurement records

$\beta_{0}=$ Constant of regression (when $X_{i}=0$ )

$X_{t}=$ Capacity of personnel involved in managing procurement records

$X_{2}=$ Adequacy of storage space for keeping procurement records

$X_{s}=$ Adequacy of equipment and facilities for keeping procurement records

$X_{*}=$ Sufficiency of security and safety measures in managing procurement records

$\varepsilon=$ error term

Whereby, $\operatorname{logit}(p)$ is the $\log$ (to base $e$ ) of the odds or likelihood ratio that the dependent variable is 1 and is defined as logit $(p)=\log _{\mathrm{e}}(p / 1-p)$. In the above model, the dependent variable is the natural logarithm of the probability of extent of proper management of procurement records $p$ divide by the probability of otherwise 
management of procurement records $(1-p)$. The model will be estimated using the Maximum Likelihood Method which maximizes the probability of getting the observed results given the fitted regression coefficients (see (O'Connell, 2006; Ferrell, 2015)). The operationalization of variables found in the given logistics regression model is given in Table 1 . Whereas, $\Upsilon=D$ is measured by nominal scales and $X$ be measured by perception indices using nominal scales (see (O’Connell, 2006; Ferrell, 2015)). That is, dependent variable (Y = D) is dichotomous nominal (that is, $1=$ YES or $\mathrm{O}=\mathrm{NO}$ ); whereas, independent variables $\left(\mathrm{X}_{1}, \mathrm{X}_{2}, \mathrm{X}_{3}\right.$, and $\left.\mathrm{X}_{4}\right)$ were measured as Likert nominal scales $(1=$ strongly disagree, $2=$ agree, $3=$ neutral, $4=$ agree, $5=$ strongly agree $)$.

Table-1. Operationalization of variables

\begin{tabular}{|c|c|c|c|c|c|}
\hline Notation & $\begin{array}{l}\text { Construct } \\
\text { Variables }\end{array}$ & $\begin{array}{l}\text { Construct } \\
\text { Indicators }\end{array}$ & Measure & Scale & Instrument \\
\hline \multirow[t]{2}{*}{$\overline{X_{t}}$} & \multirow{2}{*}{$\begin{array}{l}\text { Capacity of } \\
\text { personnel involved } \\
\text { in managing } \\
\text { procurement } \\
\text { records }\end{array}$} & Knowledge & Likert/Nominal & 5 Point Likert Scale & Questionnaire \\
\hline & & Competence & Likert/Nominal & 5 Point Likert Scale & Questionnaire \\
\hline \multirow[t]{2}{*}{$X_{2}$} & \multirow{2}{*}{$\begin{array}{l}\text { Adequacy of } \\
\text { storage space for } \\
\text { keeping } \\
\text { procurement } \\
\text { records }\end{array}$} & Availability & Likert/Nominal & 5 Point Likert Scale & Questionnaire \\
\hline & & Adequacy & Likert/Nominal & 5 Point Likert Scale & Questionnaire \\
\hline \multirow[t]{2}{*}{$X_{s}$} & \multirow[b]{2}{*}{$\begin{array}{lr}\text { Adequacy } & \text { of } \\
\text { equipment } & \text { and } \\
\text { facilities } & \text { for } \\
\text { keeping } & \\
\text { procurement } & \\
\text { records } & \end{array}$} & Availability & Likert/Nominal & 5 Point Likert Scale & Questionnaire \\
\hline & & Adequacy & Likert/Nominal & 5 Point Likert Scale & Questionnaire \\
\hline \multirow[t]{2}{*}{$X_{4}$} & \multirow{2}{*}{$\begin{array}{l}\text { Sufficiency of } \\
\text { security and safety } \\
\text { in managing } \\
\text { procurement } \\
\text { records }\end{array}$} & Availability & Likert/Nominal & 5 Point Likert Scale & Questionnaire \\
\hline & & Sufficiency & Likert/Nominal & 5 Point Likert Scale & Questionnaire \\
\hline$\Upsilon$ & $\begin{array}{l}\text { Management } \\
\text { procurement } \\
\text { records }\end{array}$ & $\begin{array}{l}\text { Proper } \\
\text { management of } \\
\text { procurement } \\
\text { records } \\
\text { otherwise }\end{array}$ & Nominal & $\begin{array}{l}\text { Dichotomous }(1= \\
\text { YES, } 0=\text { NO })\end{array}$ & Questionnaire \\
\hline
\end{tabular}

Here, the logit model model is considered due to the assumptions that:

1. Response $(Y=D)$ is binary representing either proper management of procurement records or otherwise (improper); and

2. $p(\mathrm{x})=\operatorname{Prob}\left(\Upsilon_{i}=D=1\right)$.

\subsection{Technical Considerations for Using the Logit Model}

In this section the discussion is on the relevance of the choice of variables to be used in modelling the management of procurement records with the constraining factors that the study wants to identify, establish and determine the marginal effects. Management of procurement records is considered as a binary outcome. Either properly managed procurement records or otherwise (that is, improperly managed procurement records). The dichotomous outcome suffices the use of the logit model. Logistic regression analysis predicts the value on one dependent variable from one or more independent (predicting) variables when the dependent variable is dichotomous (Foster et al., 2006). In this study, the dependent variable $(X=D)$ has two outcomes $(1=$ YES [proper] or $\mathrm{O}=\mathrm{NO}$ [improper $])$ and the independent variables $\left(X_{i}\right)$ have a number of attributes with Likert's scales 
( $1=$ strongly disagree, $2=$ disagree, $3=$ neutral, $4=$ agree, $5=$ strongly agree). Here, the logit has been considered rather than the probit due to their assumptions on distribution of errors. Logit model assumes standard logistic distribution of errors whilst probit model assumes normal distribution of errors. The data for this study were considered nonlinear and they were not normally distributed. That is the essence of the logit model.

\subsection{Commonality Use of Marginal Effects}

Marginal effects are commonly used in practice to quantify the effect of variables on an outcome of interest. They are known as average treatment effects, average partial effects, and average structural functions in different contexts (Wooldridge, 2002; Blundell and Powell, 2003). In panel data, for example, marginal effects average over unobserved individual heterogeneity. Important results on identification of marginal effects in nonlinear panel data using control variable are given in Chamberlain (1984). This paper gives identification and estimation results for marginal effects of explanatory independent variables on the dependent dichotomous variable. It is sometimes thought that marginal effects can be estimated using linear fixed effects, as shown by Hahn (2001) in an example and Wooldridge (2002) under strong independence conditions. It turns out that the situation is more complicated. The marginal effect may not be identified (Chernozhukov et al., 2009). In this study, with a binary dependent variable $(\mathrm{Y}=\mathrm{D})$, the logistic regression is using the independent variables $\left(\mathrm{X}_{i}\right)$. The study has demonstrated the marginal effects of independent variables $\left(\mathrm{X}_{i}\right)$ on the dichotomous dependent variable $(\mathrm{Y}=\mathrm{D})$. The focus here is to quantify the marginal effects of the independent variables on the dependent variable and state their significant role in the management of procurement records in the Tanzania PEs.

\section{RESULTS, FINDINGS AND DISCUSSION}

\subsection{Reliability Test on the Questionnaire}

Reliability is the ability of a measurement instrument to produce the same result (answer) in the same circumstances, time after time (De Vaus, 2002). This means that if people attempted to answer the same question the same way on repeated occasions, then the instrument can be said to be reliable. Reliability can be internal or external. Internal reliability refers to the consistency of results within a particular site, and plausibility of data within that site. External reliability refers to the consistency and duplicative attributes of data across the sites (Del Castillo, 2009). In quantitative research, reliability deals with indicator's dependability, which means that the information provided by indicators does not vary as a result of the characteristics of the indicator, instrument or device itself (Gall et al., 2007). Reliability analysis was used to test the internal consistency of the research instruments for the purposes of identifying those items in the questionnaire with low correlations in order to exclude them from further analysis. Cronbach's alpha a coefficient of reliability that gives unbiased estimate of data generalizability was used to test reliability of the answered questionnaires.

The purpose of determining the reliability statistics was to test the reliability of the structured questionnaire (see APPENDIX) that was used to collect data on construct variables and their associated attributes. Reliability of the structured questionnaire refers to its ability to produce consistent and stable measurements. Reliability, as explained by Bagozzi (1994) can be seen from two angles, namely: reliability (the extent of accuracy) and unreliability (the extent of inaccuracy). The most common reliability coefficient is the Cronbach's alpha which estimates internal consistency by determining how all items on a test relate to all other items and to the total test internal coherence of data. The reliability is expressed as a coefficient between 0 and 1 . The higher the coefficient, the more reliable is the test. To ensure the reliability of the instrument, Cronbach's alpha was used to test the reliability of the proposed constructs (Table 2 ). 
Table-2. Reliability test results

\begin{tabular}{l|l|l|l|l}
\hline Construct Variables & $\begin{array}{l}\text { Number of } \\
\text { Itemised } \\
\text { Attributes }\end{array}$ & $\begin{array}{l}\text { Reliability } \\
\text { Cronbach's } \\
\boldsymbol{\alpha}\end{array}$ & $\begin{array}{l}\text { Rule of thumb according } \\
\text { George and Mallery (2003) }\end{array}$ & Conclusion \\
\hline $\begin{array}{l}\text { Capacity of personnel } \\
\text { involved in managing } \\
\text { procurement records }\end{array}$ & 4 & 0.497 & Unacceptable & Unreliable \\
\hline $\begin{array}{l}\text { Adequacy of storage space for } \\
\text { keeping procurement records }\end{array}$ & 4 & 0.806 & Good & Reliable \\
\hline $\begin{array}{l}\text { Adequacy of equipment and } \\
\text { facilities for keeping } \\
\text { procurement records }\end{array}$ & 4 & 0.828 & Good & Reliable \\
\hline $\begin{array}{l}\text { Sufficiency of security and } \\
\text { safety measures in managing } \\
\text { procurement records }\end{array}$ & 4 & 0.803 & Good & Reliable \\
\hline \begin{tabular}{l} 
Source: SPSS output and analysis (2017/2018) \\
\hline
\end{tabular}
\end{tabular}

Table 2 shows the reliability of the construct variables. All construct variables depicted that the value of Cronbach's $\alpha$ were above the suggested value of 0.7 thus the study was reliable (Nunnally, 1978; Nunnally and Bernstein, 1994). On the basis of reliability test, it was supposed that the scales used in this study were reliable to capture the construct variables. The capacity of personnel involved in managing procurement records had a reliability value of 0.497 ; adequacy of storage space for keeping procurement records had a value of 0.806; adequacy of equipment and facilities for keeping procurement had a value of 0.828; and sufficiency of security and safety measures in managing procurement records had a value of 0.803 . However, a proposed construct named as "capacity of personnel involved in managing procurement records" despite of the Cronbach's $\alpha$ of 0.497 which is unacceptable (George and Mallery, 2003) was retained due to the fact that the attributes therein have a rotated component matrix (a) greater than 0.790 . Therefore, it was retained for factor analysis.

\subsection{Factor Analysis}

Factor analysis operates on the notion that measurable and observable variables can be reduced to fewer latent variables that share a common variance and are unobservable, which is known as reducing dimensionality (Bartholomew et al., 2011). These unobservable factors are not directly measured but are essentially hypothetical constructs that are used to represent variables (Cattell, 1973). Factor analysis is a technique, or more accurately, sets of techniques for identifying the underlying hypothetical constructs to account for the relationship between variables. Principal component analysis is extremely similar, and is often used as a preliminary stage to factor analysis itself (Foster et al., 2006). In this study, factor analysis was conducted in the construct variables that were found in the structured questionnaire.

Before we could have venture into logistic regression analysis, we had to conduct factor analysis in order to reduce the data into manageable constructs that are amenable for analysis. And that could yield the intended relationships between the predictors $\left(X_{i}\right)$ and the predicted $(Y)$ in the logistic regression equation. It is advised to check for the following: Whether the sample size is adequate for analysis or not and whether the correlation matrix is an identity matrix? This was done using a function in SPSS called the Kaiser-Meyer-Olkin (KMO) Measure of Sampling Adequacy (KMO Test); together with this the Bartlett's Test of Sphericity was used to test a null hypothesis that "the correlation matrix is an identity" and it was supposed to reject this hypothesis, otherwise it could not be possible to continue using factor analysis for the envisaged construct variables.

The results of both the KMO and Bartlett's Test of Sphericity have shown that the sample is adequate and that the Bartlett's Test of Sphericity yielded significant p-value < 0.05 (5\%). In all the analyses, the null hypothesis was rejected. Generally speaking, deciding what a factor is measuring, what is should be named, is a subjective process 
(Bartholomew et al., 2011). In this factors analysis, the naming of the factors has considered the essence of the constructs and what are they going to measure in the logistic regression model.

\subsection{Logit Model Analysis and Interpretations}

Basically, the logit model has been designated with the $\mathrm{D}$ as the dependent variable that is going to be explained by the FAC1_2, FAC2_2, FAC1_3, FAC2_3, FAC1_4, FAC2_4, FAC1_5, and FAC2_5 from the data file.

Table-3. Frequency for the dependent variable $(\mathrm{Y}=\mathrm{D})$

\begin{tabular}{l|l|l|l}
\hline STATA COMMAND: & tab D & & \\
\hline D: & & & \\
\hline Procurement & & & \\
\hline records are & & & \\
\hline properly & & & \\
\hline managed & Freq. & Percent & Cum. \\
\hline No & 132 & 88.00 & 88.00 \\
\hline Yes & 18 & 12.00 & 100.00 \\
\hline Total & 150 & 100.00 & \\
\hline Source: STATA output & & &
\end{tabular}

Table 3 is evident that he dependent variable D (= Procurement records are properly managed) has received $132(88 \%)$ NO responses whilst YES responses were 18 (12\%). This is an indication that procurement records are improperly managed and cared for in the studied Tanzania PEs. The logistic regression results for the dependent variable $\mathrm{D}$ is given by the following results:

\section{STATA COMMAND: logit D FAC1_2 FAC2_2 FAC1_3 FAC2_3 FAC1_4FAC2_4FAC1_5 FAC2_5}

Iteration $\mathrm{O}: \log$ likelihood $=-54.910459$

Iteration 1: $\log$ likelihood $=-32.472371$

Iteration 2: $\log$ likelihood $=-26.469163$

Iteration 3: $\log$ likelihood $=-25.870607$

Iteration 4: $\log$ likelihood $=-25.860406$

Iteration 5: $\log$ likelihood $=-25.860374$

Iteration 6: $\log$ likelihood $=-25.860374$

Logistic regression

Log likelihood $=-25.860374$

$\begin{array}{llc}\text { Number of obs } & = & 149 \\ \text { LR chi2(8) } & = & 58.10 \\ \text { Prob }>\text { chi2 } & = & 0.0000 \\ \text { Pseudo R2 } & = & 0.5290\end{array}$

Table-4. Logit model results

\begin{tabular}{l|l|l|l|l|l|l}
\hline D & Coef. & Std. Err. & $\mathbf{z}$ & $\mathbf{P}>|\mathbf{z}|$ & \multicolumn{2}{l}{$[\mathbf{9 5 \%}$ Conf. Interval] } \\
\hline FAC1_2 & .5393005 & .4568003 & 1.18 & 0.238 & -.3560117 & 1.434613 \\
\hline FAC2_2 & .37222 & .5163662 & 0.72 & 0.471 & -.6398393 & 1.384279 \\
\hline FAC1_3 & 2.020273 & .7916683 & 2.55 & 0.011 & .4686315 & 3.571914 \\
\hline FAC2_3 & 2.746539 & 1.112698 & 2.47 & 0.014 & .5656905 & 4.927387 \\
\hline FAC1_4 & -1.13302 & .781622 & -1.45 & 0.147 & -2.664972 & .3989305 \\
\hline FAC2_4 & -1.737418 & .7760048 & -2.24 & 0.025 & -3.25836 & -.2164768 \\
\hline FAC1_5 & -.595208 & .595813 & -1.00 & 0.318 & -1.76298 & .572564 \\
\hline FAC2_5 & 1.818524 & .716059 & 2.54 & 0.011 & .4150746 & 3.221974 \\
\hline _cons & -3.694547 & .7178675 & -5.15 & 0.000 & -5.101541 & -2.287553 \\
\hline Source: STATA output
\end{tabular}


The estimation results in Table 4 indicate, ceteris paribus, effects of the explanatory dependent variables on the management of procurement records. The variables FAC1_3, FAC2_3, FAC2_4 and FAC2_5 are statistically significant associated with the management of procurement records at $5 \%$ level of significance whilst variables FAC1_2, FAC2_2, FAC1_4 and FAC1_5 are not statistically significant associated with management of procurement records at $5 \%$ level of significance (no p-value $<0.05$ ).

On the significant variables, only FAC2_4 is negatively associated with management of procurement records. This is an implication that it has no significant role (influence) in the extent of proper management of procurement records. The remaining significant variables have positive coefficients meaning that they are positively related to the management of procurement records. The positively coefficient variables implies that they have significant role in the management of procurement records. For instance, the specialised knowledge, competence, and on-the-job training have significant role in proper management of procurement records.

Interpretively, Smith (2007) has stressed that personnel who are involved in records management require specialised training on the RAM. Availability and adequacy of storage space for keeping all kinds of procurement records have significant role in ensuring that procurement records are kept (stored) and preserved in area that allow proper management and care in terms of arrangement and classification in tandem with effective and efficient design and layout. Complying with these factors is the essence of proper management and care of procurement records as per (International Organisation for Standardisation (ISO), 2016).

Availability of equipment and facilities coupled with the availability and adequacy of storage space for keeping all kinds of procurement records must ensure effective and efficient procurement records keeping in terms of preservation and availability of documented and recorded procurement record files of all sorts (current, semicurrent, and non-current). Lastly, documented and recorded procurement record files require security and safety whilst in preservation. Therefore, availability and sufficiency of security and safety measures must ensure that documented and recorded procurement record files are secured into safe custody for their vitality or deliberate RAM requisites (IRMT, 1999; ISO, 2001; Read and Ginn, 2007; Smith, 2007; Read and Ginn, 2011; ISO, 2016).

\subsection{Marginal Effects and Interpretations}

The focus of the logistic regression was to determine the factors influencing and which have significant role on the management of procurement records in the Tanzania PEs. The determination was made on the significant contribution of the independent variables have on the dependent variable. It is therefore envisaged to determine the marginal effects and interpretations for each independent variable on the dependent variable in order to establish if they play significant role on the dependent variable. Table 5 is evident that there are five independent variables (FAC1_2, FAC2_2, FAC1_3, FAC2_3 and FAC2_5) that have positive marginal effects and three independent variables (FAC1_4, FAC2_4 and FAC1_5) with negative marginal effects respectively.

Table-5. Marginal effects

\begin{tabular}{|c|c|c|c|c|c|c|}
\hline \multirow{3}{*}{$\frac{\mid}{\mathrm{FAC} 1 \_2}$} & \multirow{3}{*}{$\frac{\text { Marginal }}{.0128515}$} & \multirow{3}{*}{$\frac{\text { Std. Err. }}{.0121703}$} & \multicolumn{2}{|c|}{ Delta-method } & \multirow{2}{*}{\multicolumn{2}{|c|}{ [95\% Conf. Interval] }} \\
\hline & & & \multirow{2}{*}{$\frac{\mathbf{z}}{1.06}$} & \multirow{2}{*}{$\frac{\mathbf{P}>|\mathbf{z}|}{0.291}$} & & \\
\hline & & & & & -.011002 & .0367049 \\
\hline FAC2_2 & .0088699 & .0128591 & 0.69 & 0.490 & -.0163335 & .0340734 \\
\hline FAC1_3 & .0481428 & .0299601 & 1.61 & 0.108 & -.0105779 & .1068636 \\
\hline FAC2_3 & .0654496 & .0313318 & 2.09 & 0.037 & .0040404 & .1268589 \\
\hline FAC1_4 & -.0269997 & .0214385 & -1.26 & 0.208 & -.0690183 & .0150189 \\
\hline FAC2_4 & -.0414024 & .0263913 & -1.57 & 0.117 & -.0931284 & .0103236 \\
\hline FAC1_5 & -.0141837 & .0163778 & -0.87 & 0.386 & -.0462836 & .0179162 \\
\hline $\mathrm{FAC}_{2} \_5$ & .0433352 & .0278524 & 1.56 & 0.120 & -.0112544 & .0979248 \\
\hline
\end{tabular}


Interpretively, by considering Table 5 it could be deduced that any unit change on the independent variable either increase or decrease the probability of occurrence in the dependent variable by the percentage of the coefficient in the column of the marginal (see column of marginal effects in Table 5). Thus, the interpretations for the positive marginal effects are as provided hereunder:

1. FAC1_2 (Specialised knowledge and skills on procurement records management): Procurement records managed by personnel who are knowledgeable and skilled are $1.3 \%$ more likely to be properly managed than with the unknowledgeable and unskilled personnel, ceteris paribus.

2. FAC2_2 (Competence and on-the-job training on records management): Procurement records that are managed by competent personnel and who have the on-the-job training on records management are $1.0 \%$ more likely to be properly managed than with incompetent and those that have no on-the-job training, ceteris paribus.

3. FAC1_3 (Availability of storage space for keeping all kinds of procurement records): Procuring entities with available storage space for keeping procurement records, management of procurement records improves by $4.8 \%$, ceteris paribus.

4. FAC2_3 (Adequacy of storage space for keeping all kinds of procurement records): Procuring entities with adequate storage space for keeping all kinds of procurement records, management of procurement records improves by $6.5 \%$, ceteris paribus.

5. FAC2_5 (Sufficiency of security and safety measures in managing procurement records): Procuring entities that have sufficient security and safety measures in managing procurement records, management of procurement records improves by $4.3 \%$, ceteris paribus.

On the contrary, the interpretations for the negative marginal effects of the variables (FAC1_4, FAC2_4 and FAC1_5) are provided as:

1. FAC1_4 (Availability of equipment and facilities for keeping procurement records): Procuring entities that have no equipment and facilities for keeping procurement records are $2.7 \%$ less likely to have a proper management of procurement records compared to those with available equipment and facilities, ceteris paribus.

2. FAC2_4 (Adequacy of equipment and facilities for keeping procurement records): Procuring entities that have limited equipment and facilities for keeping procurement records are $4.1 \%$ less likely to have a proper management of procurement records compared to those with adequate equipment and facilities, ceteris paribus.

3. FAC1_5 (Availability of security and safety measures in managing procurement records): Procuring entities that have no security and safety measures in managing procurement records are $1.4 \%$ less likely to have proper management of procurement records, ceteris paribus.

\section{CONCLUSION}

The objective of this study was to identify, establish and estimate results for marginal effects of the independent explanatory variables on the dependent dichotomous variable. The focus of determining the marginal effects was to determine their significant role in the management of procurement records in the Tanzania PEs. The identified, established and estimated marginal effects were, inter alia: the adequacy of storage space for keeping all kinds of procurement records; availability of storage space; sufficiency of security and safety measures; specialised knowledge and skills; competence and on-the-job training; adequacy of equipment and facilities; availability of equipment and facilities; and availability of security and safety. Results and findings (Table 5) have revealed that there are five positive marginal effects and three negative marginal effects respectively. For positive marginal effects, they indicate that any unit change on the independent variable increase the probability of occurrence in the dependent variable by the percentage of the coefficient of the marginal effects. Whilst for the negative marginal 
effects, they indicate that any unit change on the independent variable decrease the probability of occurrence in the dependent variable by the percentage of the coefficient of the marginal effects.

Based on the results and findings coupled with the interpretations of the marginal effects it is hereby concluded that: PEs that have no equipment and facilities for keeping procurement records are $2.7 \%$ less likely to have a proper management of procurement records compared to those with available equipment and facilities; PEs that have limited equipment and facilities for keeping procurement records are $4.1 \%$ less likely to have a proper management of procurement records compared to those with adequate equipment and facilities; and PEs that have no security and safety measures in managing procurement records are $1.4 \%$ less likely to have proper management of procurement records, ceteris paribus.

Whereby on the contrary: procurement records managed by personnel who are knowledgeable and skilled are $1.3 \%$ more likely to be properly managed than with the unknowledgeable and unskilled personnel; procurement records that are managed by competent personnel and who have the on-the-job training on records management are $1.0 \%$ more likely to be properly managed than with incompetent and those that have no on-the-job training; PEs with available storage space for keeping procurement records, improves management of procurement records by $4.8 \%$; PEs with adequate storage space for keeping all kinds of procurement records, improves management of procurement records by $6.5 \%$; and PEs that have sufficient security and safety measures in managing procurement records, improves management of procurement records by $4.3 \%$, ceteris paribus.

Generally, the adequacy of storage space for keeping all kinds of procurement records has a higher positive marginal effect of $6.5 \%$ in improving management of procurement records (ceteris paribus) followed by availability of storage space with positive marginal effect of $4.8 \%$, sufficiency of security and safety measures with positive marginal effect of $4.3 \%$, specialised knowledge and skills with positive marginal effect of $1.3 \%$ ), and competence and on-the-job training with positive marginal effect of $1.0 \%$. For the negative marginal effects; adequacy of equipment and facilities has negative marginal effect of $4.1 \%$ higher followed by availability of equipment and facilities by $2.7 \%$, and availability of security and safety by $1.4 \%$, ceteris paribus.

Funding: The correspondent author does hereby acknowledge the financial help of Mzumbe University that facilitated the carrying out of the research that resulted into writing of this research paper.

Competing Interests: The authors declare that they have no competing interests.

Contributors/Acknowledgement: The authors would like to Thank Dr Paul M. Nsimbila who provided academic debate on the content of the paper; and to Dr Bahati M. Ilembo who provided scholarly discussion on the context of logistic regression and marginal effects. Lastly, to Dr Geraldine A. Rasheli and Dr Leonada R. Mwagike who co-authored the paper but also provided the supervisory role for the researcher and towards writing this paper.

\section{REFERENCES}

Bagozzi, R.P., 1994. Structural equation models in marketing research: Basic principles. In R.P. Bagozzi (Ed.), Principles of Marketing Research. Oxford: Blackwell.

Bartholomew, D., M. Knotts and I. Moustaki, 2011. Latent variable models and factor analysis: A unified approach. 3rd Edn., West Sussex, UK: John Wiley \& Sons.

Blundell, R. and J.L. Powell, 2003. Endogeneity in nonparametric and semiparametric regression models. In Dewatripont, M.,

Hansen, L. P. and Turnsovsky, S.J. (Eds.), Advances in Economics and Econometrics. Cambridge: Cambridge University Press.

Cattell, R.B., 1973. Factor analysis. Westport, CT: Greenwood Press.

Chamberlain, G., 1984. Panel Data. In Griliches, Z. and Intriligator, M. (Eds.), Handbook of Econometrics. Amsterdam: NorthHolland.

Chernozhukov, V., I. Fernández-Val, J. Hahn and W. Newey, 2009. Identification and estimation of marginal effects in nonlinear panel models. 2009 Winter Econometric Society Meetings.

De Vaus, 2002. Surveys in social research. 5th Edn., London: Routledge. 
Del Castillo, E., 2009. Process optimization: A statistical approach. New York: Springer (International Series in Operations Research and Management Science).

Ferrell, F.E.J., 2015. Regression modelling strategies: With applications to linear models, logistic and ordinal regression, and survival analysis. 2nd Edn., Switzerland: International Publishing AG.

Foster, J., E. Barkus and C. Yavorsky, 2006. Understanding and using advanced statistics. London, UK: SAGE Publications Ltd. Gall, M.D., J.P. Gall and W.R. Borg, 2007. Educational research: An introduction. Boston: Pearson Education.

George, D. and P. Mallery, 2003. SPSS for Windows step by step: A simple guide and reference. 11.0 update. 4th ed. Allyn and Bacon: Boston.

Hahn, J., 2001. Comment: Binary regressors in nonlinear panel-data models with fixed effects. Journal of Business and Economic Statistics 19(1): 16-17. View at Google Scholar

International Organisation for Standardisation (ISO), 2016. ISO 15489-1: 2016. Retrieved from https://www.iso.org/standard/62542.html [Accessed 29th June, 2017].

International Records Management Trust, 2009. Fostering trust and transparency in governance: Investigating and addressing the requirements for building integrity in public sector information systems in the ICT environment. Retrieved from https://assets.publishing.service.gov.uk/media/57a08b3de5274a27b2000a47IRMT_Final_Report_Version2.pdf [Accessed 17th June 2017].

IRMT, 1999. Management of public sector records: Principles and context. London: ICA/IRMT.

IRMT, 2004. Evidence-based governance in the electronic age: Public sector reform and record keeping. Retrieved from http://www.irmt.org/documents/research_reports/project_reports/Final\%20DGF\%20Report\%20Revised.pdf

[Accessed 17th June 2017].

IRMT, 2011. Managing records as reliable evidence for ICT/ e-government and freedom of information: Tanzania country report. London: Rights and Records Institute.

ISO, 2001. ISO 15489-1: 2001. Retrieved from https://www.iso.org/standard/62542.html [Accessed 29th June, 2017].

Kendo, E. and P. Getuno, 2016. Factors affecting tendering process in state corporations: A case of Kenya Literature Bureau. International Journal of Current Business and Social Sciences, 1(5): 1-14.

Manyambula, M., 2009. Public service reform, accountability and records management: A case study of Tanzania. ESARBICA Journal, 28(1): 20-35. View at Google Scholar | View at Publisher

Naluyaga, T.M.R., 2014. Challenges facing procurement entities in complying with procurement regulations: A case of Kisarawe district council. An Unpublished Master Dissertation, Mzumbe University: Tanzania.

Namukasa, J., 2017. Records management and procurement performance: A case of NAADS programme in the central region of

Uganda. Records Management Journal, 27(1): 256-274. View at Google Scholar | View at Publisher

Njeru, S.E., 2015. Factors affecting effective implementation of procurement practices in tertiary public training institutions in

Kenya. An Unpublished PhD Thesis, Jomo Kenyatta University of Agriculture and Technology: Nairobi, Kenya.

Nunnally, J.C., 1978. Psychometric theory. 2nd Edn., New York: McGraw-Hill.

Nunnally, J.C. and I.H. Bernstein, 1994. Psychometric theory. 3rd Edn., New York: McGraw-Hill.

Nyaboke-Marendi, P., 2015. Public procurement legal framework implementation and performance of state corporations in Kenya. An Unpublished PhD Dissertation, Jomo Kenyatta University of Agriculture and Technology (JKUAT): Kenya.

O’Connell, A.A., 2006. Logistic regression models for ordinal response variables. Thousand Oaks: Sage Publications, Inc.

Read, J. and M.L. Ginn, 2007. Records management. 8th Edn., USA: Cengage Learning.

Read, J. and M.L. Ginn, 2011. Records management. 9th Edn., USA: Cengage Learning.

Republic of Uganda, 2008. The Public Procurement and Disposal of Public Asset Authority (PPDA) Compliance Audit Report. Kampala: PPDA.

RoU, 2009. The Public Procurement and Disposal of Public Asset Authority (PPDA) Compliance Audit Report. Kampala: PPDA. 
RoU, 2010. The Public Procurement and Disposal of Public Asset Authority (PPDA) Baseline Survey Report. Kampala: PPDA. Smith, K., 2007. Public sector records management: A practical guide. Ashgate Publishing Limited.

Stephano, F., 2014. Challenges facing public institutions in implementation of public procurement act No. 21 of 2004: The case of the Office of the registrar of political parties. An Unpublished Master Dissertation, Mzumbe University: Tanzania.

Thurston, A., 2005. Fostering trust and transparency through information systems. ACARM Newsletter, 36. Retrieved from http://www.acarm.org [Accessed 18th December 2017].

Tumuhairwe, R. and A. Ahimbisibwe, 2016. Procurement records compliance, effective risk management and records management performance: Evidence from Ugandan public procuring and disposing entities. Records Management Journal, 26(1): 83-101. View at Google Scholar | View at Publisher

United Republic of Tanzania, 2014a. Public Procurement Regulatory Authority (PPRA) Annual Performance Evaluation Report for the Financial Year 2013/2014. Dar es Salaam, Tanzania: PPRA.

URT, 2014b. Annual General Report of the Controller and Auditor General for the Financial Year ended 30th June, 2013. Dar es Salaam, Tanzania: NAOT.

URT, 2015a. Public Procurement Regulatory Authority (PPRA) Annual Performance Evaluation Report for the Financial Year 2014/2015. Dar es Salaam, Tanzania: PPRA.

URT, 2015b. Annual General Report of the Controller and Auditor General for the Financial Year ended 30th June, 2014. Dar es Salaam, Tanzania: NAOT.

URT, 2016a. Public Procurement Regulatory Authority (PPRA) Annual Performance Evaluation Report for the Financial Year 2015/2016. Dar es Salaam, Tanzania: PPRA.

URT, 2016b. Annual General Report of the Controller and Auditor General for the Financial Year ended 30th June, 2015. Dar es Salaam, Tanzania: NAOT.

URT, 2017a. Public Procurement Regulatory Authority (PPRA) Annual Performance Evaluation Report for the Financial Year 2016/2017. Dar es Salaam, Tanzania: PPRA.

URT, 2017b. Annual General Report of the Controller and Auditor General for the Financial Year ended 30th June, 2016. Dar es Salaam, Tanzania: NAOT.

WB and IRMT, 2000. Managing records as the basis for effective service delivery and public accountability in development: An introduction to core principles for staff of the World Bank and its partners. Information Solutions Group, World Bank Publications No. 4700.

Weisinger, D., 2011. Alfresco 3 records management. Birmingham: Packet Publishing Ltd.

Williams, C., 2006. Managing archives: Foundations, principles and practice. Hartcourt: Chandos Publishing (Oxford) Limited.

Wooldridge, J.M., 2002. Econometric analysis of cross section and panel data. Cambridge, MA: MIT Press.

World Bank and International Records Management Trust, 2005. Fostering trust and transparent through information systems. Public sector. PREM Notes, 97. Retrieved from http://www1.worldbank.org/prem/PREMNotes/premnote97.pdf [Accessed 12th July 2017].

\section{APPENDIX: Structured Questionnaire}

A: General Information (please tick $[\sqrt{ }]$ where appropriate)

1. Work station: PMU [.....]; User Department [..... ; Other [.....] (specify)

2. Sex: Male $[\ldots . . .$.$] ; Female [\ldots . .$.

3. What is your level of education?

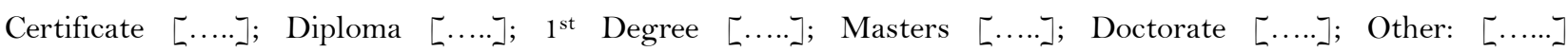
(specify): 


\section{B: Perception of Respondents on the Factors for Proper Management of Procurement Records}

In the table below, circle your opinion in the given statements on factors for proper management of procurement records in your organisation.

Key: 1 = Strongly Disagree; $2=$ Disagree; $3=$ Neutral; $4=$ Agree; $5=$ Strongly Agree

\begin{tabular}{|c|c|c|c|c|c|c|}
\hline $\mathbf{S} / \mathbf{N}$ & Construct/Attributes & \multicolumn{5}{|c|}{$\begin{array}{l}\text { Respondent's } \\
\text { Opinion }\end{array}$} \\
\hline \multicolumn{7}{|c|}{ Capacity of personnel involved in managing procurement records } \\
\hline 1 & $\begin{array}{l}\text { Management of procurement records is done by personnel who have the specialised } \\
\text { knowledge in the procurement functional activities }\end{array}$ & 1 & 2 & 3 & 4 & 5 \\
\hline 2 & $\begin{array}{l}\text { Personnel who are managing procurement records have the required records } \\
\text { management skills }\end{array}$ & 1 & 2 & 3 & 4 & 5 \\
\hline 3 & $\begin{array}{l}\text { Procurement records management is executed by personnel who have the required } \\
\text { competences on records management }\end{array}$ & 1 & 2 & 3 & 4 & 5 \\
\hline 4 & $\begin{array}{l}\text { Personnel who are managing procurement records do receive specialised on-the-job } \\
\text { training on records management practices }\end{array}$ & 1 & 2 & 3 & 4 & 5 \\
\hline \multicolumn{7}{|c|}{ Adequacy of storage space for keeping procurement records } \\
\hline 1 & There is storage space for keeping procurement records & 1 & 2 & 3 & 4 & 5 \\
\hline 2 & There is adequate storage space for keeping procurement records & 1 & 2 & 3 & 4 & 5 \\
\hline 3 & There is storage space for keeping all kinds of procurement records & 1 & 2 & 3 & 4 & 5 \\
\hline 4 & There is adequate storage space for keeping all kinds of procurement records & 1 & 2 & 3 & 4 & 5 \\
\hline \multicolumn{7}{|c|}{ Adequacy of equipment and facilities for keeping procurement records } \\
\hline 1 & There is equipment for keeping procurement records & 1 & 2 & 3 & 4 & 5 \\
\hline 2 & There is adequate equipment for keeping all kinds of procurement records & 1 & 2 & 3 & 4 & 5 \\
\hline 3 & There are facilities for keeping procurement records & 1 & 2 & 3 & 4 & 5 \\
\hline 4 & There are adequate facilities for keeping all kinds of procurement records & 1 & 2 & 3 & 4 & 5 \\
\hline \multicolumn{7}{|c|}{ Sufficiency of security and safety measures in managing procurement records } \\
\hline 1 & There are security measures in managing procurement records & 1 & 2 & 3 & 4 & 5 \\
\hline 2 & There are sufficient security measures in managing procurement records & 1 & 2 & 3 & 4 & 5 \\
\hline 3 & There are safety measures in managing procurement records & 1 & 2 & 3 & 4 & 5 \\
\hline 4 & There are sufficient safety measures in managing procurement records & 1 & 2 & 3 & 4 & 5 \\
\hline
\end{tabular}

\section{C: Perception of Respondents on Proper Management of Procurement Records}

In the table below, circle your assessment on proper management of procurement records in your organisation.

Key: 1 = YES; $0=\mathrm{NO}$

\begin{tabular}{l|l|l}
\hline Statement & \multicolumn{2}{|l}{ Respondent's Opinion } \\
\hline Procurement records are properly managed & 1 & 0 \\
\hline
\end{tabular}

